\title{
Investigation of Turkish dentists' clinical attitudes and behaviors towards the COVID-19 pandemic: a survey study
}

\section{Gülsüm DURUK(a) \\ Zekiye Şeyma GÜMÜŞBOĞA ${ }^{(a)}$ Cemil ÇOLAK(b) (iD)}

(a)|nönü University, Faculty of Dentistry, Department of Pediatric Dentistry, Malatya, Turkey.

(b)|nönü University, Faculty of Medicine, Department of Biostatistics and Medical Informatics, Malatya, Turkey

Declaration of Interests: The authors certify that they have no commercial or associative interest that represents a conflict of interest in connection with the manuscript.

\section{Corresponding Author:}

Gülsüm Duruk

E-mail:durukgulsum@yahoo.com

https://doi.org/10.1590/1807-3107bor-2020.vol34.0054

Submitted: April 1, 2020

Accepted for publication: April 20, 2020

Last revision: May 13, 2020

\begin{abstract}
Currently, the whole world is under the threat of the COVID-19 pandemic, and dentists are at high risk. The aim of this study was to investigate what kind of precautions Turkish dentists take in dental clinics during the COVID-19 pandemic. The study population consisted of dentists in Turkey. An online questionnaire (23 questions-57 items) was sent to a sample of Turkish dentists from March 16 to March 20, 2020. The questionnaire comprised a series of questions about dentists' demographic characteristics, their concerns, and the measures taken in dental clinics against COVID-19. This study included a total of 1,958 Turkish dentists. A total of 1,274 (65.1\%) were general dentists, and $684(34.9 \%)$ were specialists. Five hundred twenty-two (26.7\%) dentists attended an informational meeting on COVID-19. Of these dentists, $69.8 \%$ were aware of COVID-19 according to their self-assessed knowledge scores. More than $90 \%$ of the dentists were concerned about themselves and their families. Only $12 \%$ of the dentists wore an N95 mask. Although Turkish dentists took some precautionary measures, they did not take enough precautions to protect themselves, the dental staff, and other patients from COVID-19. As the number of COVID-19 cases increased, the measures taken slightly increased in dental clinics as well. Dentists are strongly recommended to take maximum precautions in the clinical setting. The guidelines about the COVID-19 pandemic should be sent to all dentists by the regional and national dental associations.
\end{abstract}

Keywords: COVID-19; Coronavirus; Dentistry; Dentists; Infections.

\section{Introduction}

The coronavirus disease-2019 (COVID-19) outbreak began to be observed for the first time in the city of Wuhan, China, and has then become a major public health problem not only for China, but also for other countries around the world, ${ }^{1}$ prompting the World Health Organization (WHO) to declare COVID-19 a pandemic on March 11, 2020. ${ }^{2}$ A new type of coronavirus was isolated on January 7, 2020, and the influenza virus, avian influenza virus, adenovirus, severe acute respiratory syndrome coronavirus (SARS-CoV), and Middle East respiratory syndrome coronavirus (MERS-CoV) were excluded as possible pathogens. This virus was initially called "new coronavirus" (nCoV). ${ }^{3}$ Finally, the pathogen has been called SARS-CoV-2. ${ }^{4}$ 
The first officially known case of COVID-19 in Turkey was detected on March 10, 2020. After this date, the number of cases has increased day by day according to $\mathrm{WHO}$ data. ${ }^{5}$

Its human-to-human transmission occurs through airborne droplets of respiratory secretions from an infected individual and through contact with an infected person or contaminated surface. It has not yet been proven that it is transmitted by blood or saliva. However, like in other diseases that have been proven to be transmitted by blood or saliva, such as human immunodeficiency virus infection/acquired immune deficiency syndrome (HIV/AIDS), hepatitis $\mathrm{C}$ virus (HCV), and hepatitis B virus (HBV), it has been suggested 2019-nCoV could also be transmitted in similar ways. ${ }^{6}$

Although the average incubation period of 2019$\mathrm{nCoV}$ is estimated to be 5 to 6 days, there is some evidence showing that this period could be as long as 14 days. Despite reports indicating that it could extend up to 24 days, a 14-day period is the accepted time frame to make medical observations and put those who have been (potentially) exposed to the infection in quarantine. ${ }^{7}$

2019-nCoV can live on surfaces for a few hours or up to several days, depending on the type of surface, ambient temperature, or humidity. ${ }^{8}$ Based on observations, although people of all ages are susceptible to this infectious disease, when the modes of transmission of this pandemic were examined, it was observed that those who are in close contact with symptomatic/asymptomatic COVID-19 patients, including healthcare staff and other patients in hospitals, are at higher risk of acquiring this infection. ${ }^{9}$ In particular, when working procedures in dental clinics are considered, the spread of this infection can be high among dentists and their patients.

There is an urgent need for strict and effective infection control protocols for dental practices and hospitals in countries/regions affected by COVID-19. There are guidelines recommended by the Centers for Disease Control and Prevention (CDC), the American Dental Association (ADA), and WHO for dentists and dental staff to control the spread of COVID-19,1,10

If an individual has been in pandemic regions in the past 14 days, quarantine is recommended for at least 14 days. Non-emergency dental care should be suspended in the regions where COVID-19 has spread. ${ }^{11}$ Oral emergencies are defined as oral diseases that rapidly occur and develop in a short time and require immediate treatment, such as toothache, dental trauma, temporomandibular joint dislocation, oral and maxillofacial trauma, and infection. ${ }^{12,13}$

High-speed rotary handpieces and ultrasonic instruments produce aerosols and droplets that are contaminated with body fluids (blood, saliva, etc.). Therefore, dentists may be contaminated with various pathogenic microorganisms or exposed to contaminated clinical settings. 2019-nCoV infection may also occur through direct contact between contaminated hands and the damaged mucosa when the defensive barrier is removed as a result of the fact that sharp tools damage the epithelial barrier of the mucosa and cut and pierce the mucosa. ${ }^{11}$

It is not recommended that a patient with COVID-19, who is in the acute febrile phase of the disease, visit a dental clinic. In terms of a potential risk of infection, the body temperature of all patients admitted to the dental clinic should be measured by a contact-free forehead thermometer in the first place, and it is recommended that a form with questions about the risk factors for a potential infection be filled out before directing patients to the dental chair, and patients are recommended to be seated in a dental chair only if all the parameters in this form are negative. ${ }^{14}$ Before the oral examination, patients can use mouthrinses such as povidone-iodine $(1 \%)$, cetylpyridinium chloride $(0.05 \% \sim 0.10 \%)$, or mouthrinses containing essential oil components that can effectively reduce droplets and aerosols generated during dental procedures. ${ }^{15}$

COVID-19 can be transmitted by the oral-fecal route, which also reveals the importance of hand hygiene. Failure to pay maximum attention to hand hygiene is one of the major factors in the spread of the disease. Therefore, additional supplements such as hand sanitizers are absolutely required for dentists who cannot wash their hands frequently. ${ }^{14}$

Dentists are recommended to take personal precautions (mask, goggles, etc.) in order to protect themselves from the droplets/aerosols generated during dental procedures. ${ }^{9}$ Since the transmission of airborne droplet infection is considered the main 
mode of spread, especially in dental clinics and hospitals, protective equipment, including safety goggles, masks, gloves, face shields, and protective outerwear, is strongly recommended to dentists for all health care services in order to create a barrier against the virus. ${ }^{14}$

Nowadays, when the world struggles with the COVID-19 pandemic, dentists have to change their routine clinical attitudes and behaviors. The aim of this study was to investigate whether Turkish dentists who are actively performing their duties have made any possible changes in their attitudes and behaviors towards COVID-19 at their dental clinics before or during routine dental procedures and to raise awareness about the importance of such changes.

\section{Methodology}

The study was approved by the Non-Interventional Clinical Research Ethics Committee of Inonu University, Malatya, Turkey (process 2020/592).

A new questionnaire about COVID-19 was developed for the study. Firstly, we carried out a literature search in Turkish and English and looked at guidelines by using the keywords "COVID-19", "Coronavirus", "dentistry", and "dental treatment". Then, a questionnaire, consisting of 22 questions (56 items), was compiled from the relevant sources. Google forms were used to create the questionnaire.

The content adequacy of the questionnaire was examined by experts to assess how clear the wording of the items was prior to the main study. The questions were sent to five experts (two pediatric dentists, one periodontist, one general dentist, and one biostatistician). Based on the comments made by these experts, one question was added. Then, the final 23 questions ( 57 items) were tested by two experts (one pediatric dentist and one general dentist) to check whether the questions were understandable and consistent with the conceptual framework. Finally, the questionnaire was sent to a Turkish language expert for validation, and the questionnaire was concluded in this stage.

The final online questionnaire was sent to all dentists in Turkey whose contact information had been provided by email, WhatsApp, and private social networking platforms, such as Facebook, Instagram, etc. In addition, the questionnaire was distributed via Facebook to groups that are currently very active online forums for dentists in Turkey. A total of 1,958 Turkish dentists, all volunteers, answered the questionnaire. The number of volunteer dentists participating in the survey was larger than the required sample size (see details below) calculated for this study. The calculated sample size was determined proportionally based on the number of dentists in each specialty area in Turkey. The survey data were collected from March 16 to March 20, 2020.

\section{Statistical analyses}

The power analysis estimated that surveys with 1,454 or more individuals needed to have a $98 \%$ confidence interval, a population size of 40,429 individuals, with the real value within $\pm 3 \%$ of the surveyed value. However, in order to increase the reliability of the findings of this study, 1,958 individuals who answered the web-based questionnaire during the survey application period were included. Based on the stratified random sampling method, the minimum number required for each specialty area was determined by considering the targeted sample size.

The data were expressed as mean and standard deviation or frequency with percentage values for overall variables. Proportions were compared by the z-test, whenever appropriate. Pairwise comparisons of the proportions were made using Bonferroni's method. $\mathrm{P}<0.05$ values were considered to be significant. IBM SPSS Statistics for Windows, version 26.0, was used for the statistical analyses.

A multilayer perceptron (MLP) artificial neural network (ANN) model was constructed to associate the dentists' self-assessed COVID-19 knowledge score (target variable) with the related variables such as the questions in the survey and the date on which the questionnaire was filled out (input variables). The whole data were randomly divided into a training dataset $(70 \%)$ and testing dataset (30\%), respectively. The importance values for the input variables were calculated by using the MLP ANN model and ranked in descending order. 


\section{Results}

The mean age of the 1,958 participants was $32.5 \pm 23.5$ (20-74) years, $70 \%$ were female, $53.3 \%$ were single, $67.7 \%$ were living with an immediate family member, $5.7 \%$ were living with an extended family member, $21.9 \%$ were living alone, and $33.9 \%$ had a child/children. In addition, $3.3 \%$ of the participants had traveled abroad in the past month, $18.2 \%$ had had face-to-face contact with someone who had traveled abroad in the past month, and $33.9 \%$ presented with some medical problem.

Regarding dental specialties, $65.1 \%$ were general dentists, $3.8 \%$ were maxillofacial surgeons, $5.2 \%$ were endodontists, $2 \%$ were oral diagnosis and radiology specialists, $3.4 \%$ were orthodontists, $10.3 \%$ were pediatric dentists, $4.3 \%$ were prosthodontists, $3.6 \%$ were periodontists, and $2.3 \%$ were restorative dentistry specialists. The survey response rates by Turkish general dentists and specialists were $3.7 \%, 7.6 \%, 14.7 \%, 9.8 \%$, $5.5 \%, 28 \%, 8.2 \%, 9 \%$, and $8.3 \%$, respectively.

Of the study participants, $29.8 \%$ were working in a private hospital/clinic, $43.6 \%$ were working in a public hospital, and $26.6 \%$ were working in a university.

The dentists' self-assessed COVID-19 knowledge scores from 1 to 5 were $59.2 \%, 15.3 \%, 8.8 \%, 9.9 \%$, and $6.8 \%$, respectively.

Most of the dentists answered "Yes" to three questions (Q20, Q21, and Q22) (Table 1).

When asked about the source of information about COVID-19, 96.27\% answered that they received this information from "physicians' personal websites/social media accounts". This answer had the highest percentage compared to others. Only $26.65 \%$ of the dentists attended an informational meeting on COVID-19.

The distribution of the participants' answers to some questions - Q12, Q13, Q14, Q15, Q16, Q19, and Q23 - is presented in Table 2.

The percentage distributions of the answers regarding the changes made by dentists and institutions for patient admission during the 5-day data collection are shown in Table 3.

The importance levels of the related variables, such as the questions in the survey and the date on which the questionnaire was filled out, for the dentists' self-assessed COVID-19 knowledge score, according to the MLP ANN model, are presented in Table 4 . The question with the highest importance level was "As a dentist, do you inform your patients about COVID-19?" (15.39\%), whereas the variable with the lowest importance level was "marital status" (0.03\%) (Table 4).

According to the WHO-Global Dashboard, ${ }^{5}$ the total number of confirmed cases/new cases of COVID-19 for 16-20 March 2020, when this survey was conducted, is presented in Table 5.

\section{Discussion}

This survey study raises awareness about taking the necessary measures as soon as possible and provides insight into whether dentists in Turkey have made any changes in their routine dental treatment practices since the COVID-19 pandemic started to spread in our country in March 2020.

The first officially known case of COVID-19 in Turkey was detected on March 10, 2020, and this study was carried out using the web-based survey designed between March 16 and 20, 2020. There was an increase in the number of confirmed cases on these dates.

Even though data collection was limited to 5 days, participation in the survey was quite high. More participants than the minimum sample size calculated for the study $(n=1,454)$ were included $(n=1,958)$ so that the validity and reliability of the obtained results could be increased. This study reflects the dentists' attitudes and behaviors throughout Turkey since it included the sample size calculated using power analysis. Although participation in the survey required volunteering, participation in the survey was quite high, possibly due to the fact that COVID-19 is a current issue and dentists are worried about and interested in this infection as they do not know exactly how they should act or behave towards it.

According to some variables investigated in this study (sociodemographic status, medical status, traveling abroad, the score of dentists' self-assessed knowledge, shown in Table 1), the percentage of professionals psychologically affected by COVID-19 was generally over $80 \%$. Psychological distress was described by $67.6 \%$ of maxillofacial surgeons and 


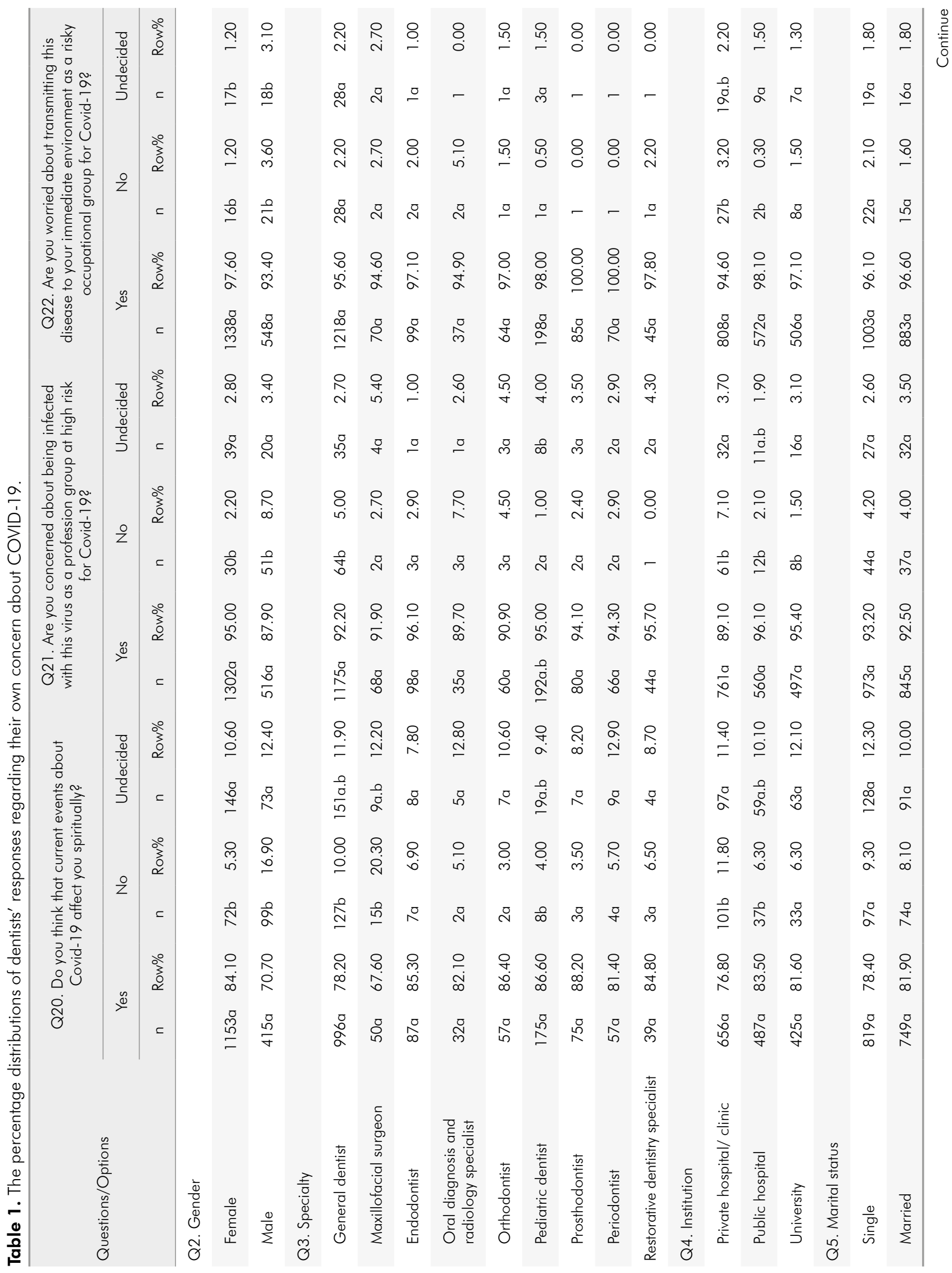




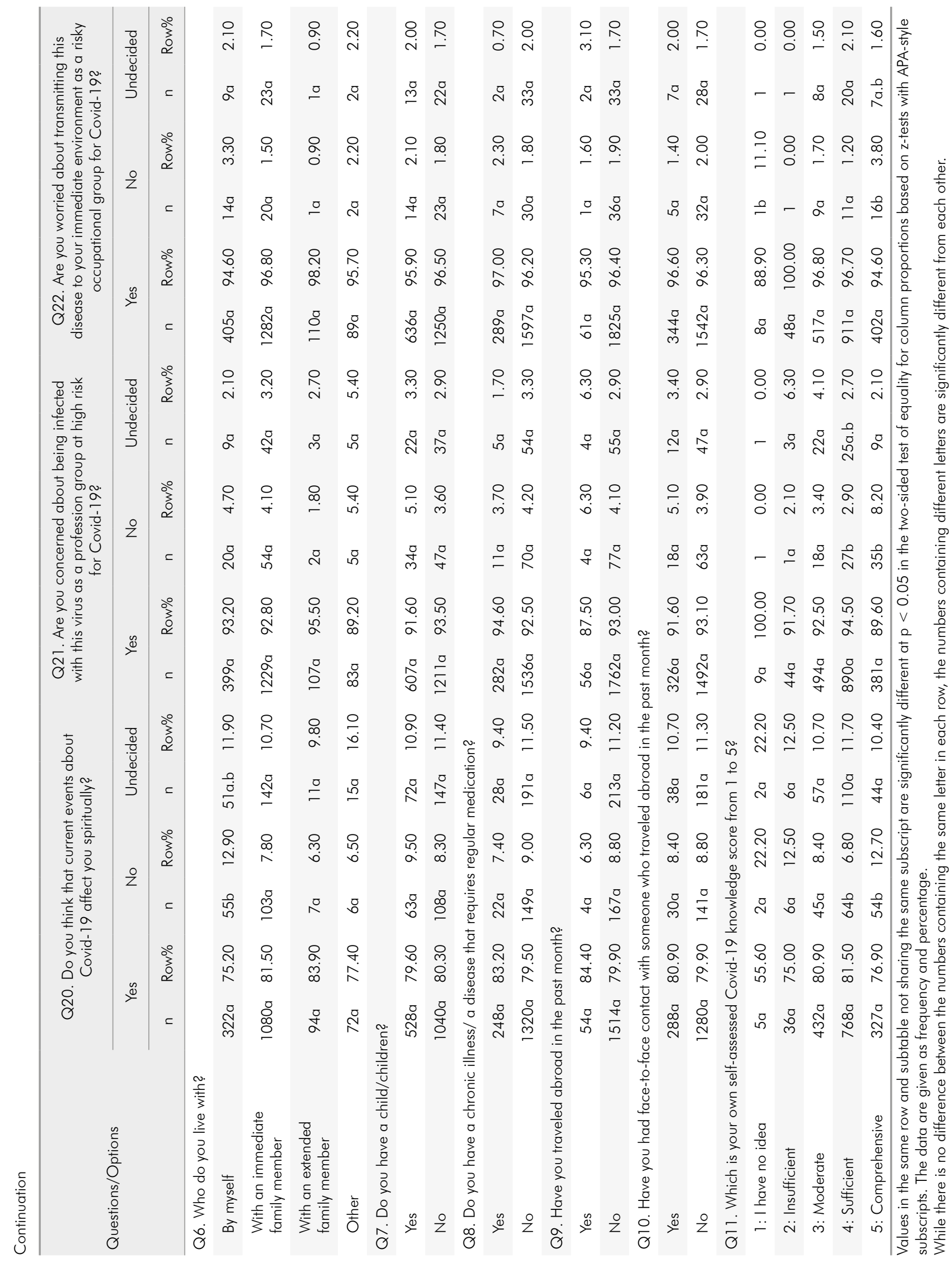


Table 2. The percentage distributions of the participants' responses to some questions.

\begin{tabular}{|c|c|c|}
\hline Questions & $\mathrm{n}$ & $\%$ \\
\hline \multicolumn{3}{|l|}{ Q12. Where do you receive the information about Covid-19 from? (multiple choice) } \\
\hline $\begin{array}{l}\text { The websites of official entities such as the Ministry of Health, WHO, and professional organizations, and/or their social } \\
\text { media accounts }\end{array}$ & 1789 & 91.37 \\
\hline Physicians' personal websites/ social media accounts & 1885 & 96.27 \\
\hline TV & 1061 & 54.19 \\
\hline From medical books, medical journals or articles (printed or online) & 553 & 28.24 \\
\hline Events such as seminars/ meetings/ congresses held by institutions & 449 & 22.93 \\
\hline Communication groups such as WhatsApp, Viber & 887 & 45.3 \\
\hline Other & 169 & 8.63 \\
\hline I have not received any information so far & 4 & 0.20 \\
\hline \multicolumn{3}{|l|}{ Q13. Have you attended an informational meeting on Covid-19? } \\
\hline Yes & 522 & 26.65 \\
\hline No & 1436 & 73.34 \\
\hline \multicolumn{3}{|l|}{ Q14. Which of the following measures do you implement in your daily life against Covid-19? } \\
\hline Mask & 1241 & 63.38 \\
\hline Gloves & 1056 & 53.93 \\
\hline Frequent hand washing & 1930 & 98.57 \\
\hline Using Cologne / Colonial tissue etc. & 1618 & 82.64 \\
\hline No handshaking / no embracing / no kissing & 1804 & 92.13 \\
\hline Not being in crowded places & 1601 & 81.77 \\
\hline Frequent ventilation for a healthy indoor environment & 1696 & 86.62 \\
\hline Other & 291 & 14.86 \\
\hline None & 5 & 0.26 \\
\hline \multicolumn{3}{|l|}{ Q15. Which of the following measures do you implement in your professional life against Covid-19? (multiple choice) } \\
\hline Mask & 1682 & 85.90 \\
\hline N95 Mask & 242 & 12.36 \\
\hline Gloves & 1891 & 96.58 \\
\hline Goggles & 1048 & 53.52 \\
\hline Face shield & 1377 & 70.33 \\
\hline Bonnet & 1099 & 56.13 \\
\hline Disposable apron & 892 & 45.56 \\
\hline Frequent hand washing & 1897 & 96.88 \\
\hline Frequent hand sanitizing & 1624 & 82.94 \\
\hline Other & 183 & 9.35 \\
\hline None & 5 & 0.26 \\
\hline \multicolumn{3}{|l|}{ Q16. Which of the following measures do you apply to your patients in your professional life against Covid-19? (multiple choice) } \\
\hline Before a dental procedure, I ask patients if they have symptoms such as a fever and a cough & 83 & 4.24 \\
\hline I'm applying a rubber dam & 271 & 13.84 \\
\hline Before a dental procedure, I have patients rinse their mouth with an antiseptic mouthwash containing chlorhexidine & 202 & 10.32 \\
\hline Before a dental procedure, I have patients rinse their mouth with an antiseptic mouthwash containing $1 \%$ hydrogen peroxide & 302 & 15.42 \\
\hline Before a dental procedure, I have patients rinse their mouth with an antiseptic mouthwash containing $0.2 \%$ povidone (Batticon) & 714 & 36.47 \\
\hline I use a strong absorbent system during the process & 1249 & 63.79 \\
\hline I avoid all the procedures that will create an aerosol as much as possible & 978 & 49.95 \\
\hline I apply the 14-day waiting rule to potentially infected patients & 167 & 8.53 \\
\hline Other & 173 & 8.84 \\
\hline None & 1313 & 67.06 \\
\hline \multicolumn{3}{|l|}{ Q19. What are the problems you have encountered at work during this Covid-19 pandemic? (multiple choice) } \\
\hline I have difficulty accessing protective equipment (mask, face shield etc.) & 908 & 46.37 \\
\hline I don't think that my fellow physicians' awareness of this subject has reached the sufficient level yet & 647 & 33.04 \\
\hline I think the awareness level of this subject is low among the assistant healthcare professionals & 615 & 31.41 \\
\hline I think patients' awareness of this subject is low & 1716 & 87.64 \\
\hline Other & 130 & 6.64 \\
\hline I have not encountered any problems & 139 & 7.10 \\
\hline \multicolumn{3}{|l|}{ Q23. As a dentist, do you inform your patients about Covid-19? } \\
\hline Yes & 1624 & 82.94 \\
\hline No & 334 & 17.06 \\
\hline
\end{tabular}


Investigation of Turkish dentists' clinical attitudes and behaviors towards the COVID-19 pandemic: a survey study

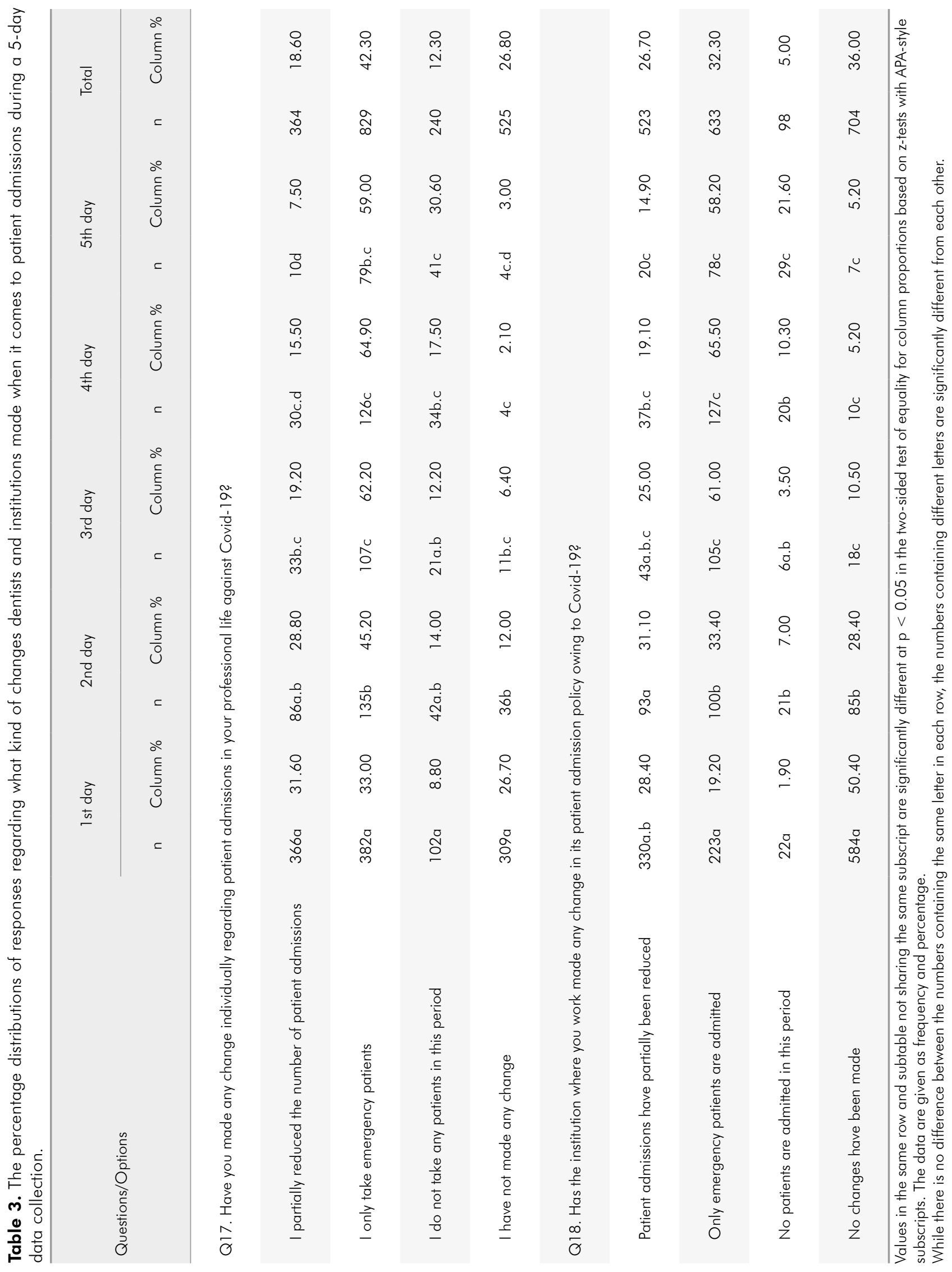


Table 4. The importance levels of the related variables for the dentists' self-assessed COVID-19 knowledge score according to the MLP ANN model.

\begin{tabular}{|c|c|}
\hline The variables & $\begin{array}{c}\text { Importance } \\
\text { level (\%) }\end{array}$ \\
\hline Q23. As a dentist, do you inform your patients about Covid-19? & $15.39 \%$ \\
\hline Q12. Where do you receive the information about Covid-19 from? (multiple choice) & $7.79 \%$ \\
\hline Q1. Age & $7.44 \%$ \\
\hline Q15. Which of the following measures do you implement in your professional life against Covid-19? (multiple choice) & $7.42 \%$ \\
\hline Q19. What are the problems you have encountered at work during this Covid-19 pandemic? (multiple choice) & $7.34 \%$ \\
\hline Q16. Which of the following measures do you apply to your patients in your professional life against the Covid-19? (multiple choice) & $6.67 \%$ \\
\hline Q14. Which of the following measures do you implement in your daily life against Covid-19? (multiple choice) & $6.58 \%$ \\
\hline Q17. Have you made any change individually regarding patient admissions in your professional life against Covid-19? & $5.33 \%$ \\
\hline Q22. Are you worried about transmitting this disease to your immediate environment as a risky occupational group for Covid-19? & $4.80 \%$ \\
\hline Q4. Institution & $3.91 \%$ \\
\hline Q3. Specialty & $3.75 \%$ \\
\hline Q6. Who do you live with? & $3.51 \%$ \\
\hline Q2. Gender & $3.38 \%$ \\
\hline Q7. Do you have a child/ children? & $2.89 \%$ \\
\hline Q18. Has the institution where you work made any change in its patient admission policy owing to Covid-19? & $2.88 \%$ \\
\hline The day on which the questionnaire was filled out. & $2.35 \%$ \\
\hline Q10. Have you had face-to-face contact with someone who traveled abroad in the past month? & $2.00 \%$ \\
\hline Q8. Do you have a chronic illness/a disease that requires regular medication? & $1.62 \%$ \\
\hline Q13. Have you attended an informational meeting on Covid-19? & $1.54 \%$ \\
\hline Q21. Are you concerned about being infected with this virus as a profession group at high risk for Covid-19? & $1.35 \%$ \\
\hline Q9. Have you traveled abroad in the past month? & $1.12 \%$ \\
\hline Q20. Do you think that current events about Covid-19 affect you spiritually? & $0.91 \%$ \\
\hline Q5. Marital status & $0.03 \%$ \\
\hline Total & $100 \%$ \\
\hline
\end{tabular}

Table 5. The number of COVID-19 cases day by day in Turkey at the time of the data collection of the present study according to WHO.

\begin{tabular}{lccccc}
\hline Date & Total confirmed cases & Total confirmed new cases & Total deaths & Total new deaths & Days since last reported case \\
\hline $16 / 03 / 2020$ & 5 & 0 & 0 & 0 & 2 \\
$17 / 03 / 2020$ & 47 & 42 & 0 & 0 & 0 \\
$18 / 03 / 2020$ & 47 & 0 & 0 & 0 & 1 \\
$19 / 03 / 2020$ & 191 & 51 & 2 & 1 & 1 \\
$20 / 03 / 2020$ & 670 & 479 & 9 & 7 & 0 \\
\hline
\end{tabular}

$78.2 \%$ of general dentists. Psychological distress increased as the level of knowledge about COVID-19 increased, ranging from $55.6 \%$ to $81.5 \%$.

According to the variables discussed in Table 1, while the percentage of dentists who were concerned about getting infected with COVID-19 was over $90 \%$, the percentage of those who were concerned about carrying this virus to their families was over 95\%, which means that dentists were very concerned about themselves and their families. It is quite normal for dentists to be concerned about getting infected with 2019-nCoV and transmitting it to those around them. In a recent clinical study, $29 \%$ of 138 hospitalized patients with 2019-nCoV-infected pneumonia in Wuhan, China, were healthcare team members. ${ }^{16}$

The dentists reported that they had access to information about COVID-19 mostly from "physicians' personal websites/social media accounts (96.27\%)" 
and from "the websites of official entities such as the Ministry of Health, WHO, and professional organizations, and/or their social media accounts $(91.37 \%)^{\prime \prime}$. In order to be able to control the spread of COVID-19, it is extremely important that the sources from which physicians can obtain the necessary information be reliable and informative enough to enable them to assess the situations they often encounter professionally with regard to COVID-19. For the most accurate and reliable information, dental professionals should only access the websites of official organizations.

Unfortunately, the percentage of Turkish dentists who attended informational meetings on COVID-19 was $26.65 \%$, which is too low for dentists who are at high risk of COVID-19. The number of these meetings should be increased, and participation in meetings should be mandatory for dentists.

Coronaviruses can persist on inanimate surfaces such as metal, glass, or plastic for up to 9 days, but they can be efficiently inactivated by using surface disinfection products with $62-71 \%$ ethanol, $0.5 \%$ hydrogen peroxide, or $0.1 \%$ sodium hypochlorite within 1 minute. ${ }^{17}$ If soap and water are not available and hands are not visibly dirty, an alcohol-based hand sanitizer that contains at least $60 \%$ alcohol can be used. However, if hands are visibly dirty, they should always be washed with soap and water. ${ }^{18}$

In this study, "frequent hand washing (98.57\%)" and "no handshaking/no embracing/no kissing (92.13\%)" were the most important measures against COVID-19 taken by dentists in their daily lives. Professional measures included "more frequent hand washing (96.88\%)", "wearing gloves (96.58\%)", and "wearing a mask $(85.90 \%)$ ". Wearing an N95 mask was one of the measures taken at least by $12.36 \%$. This low rate could be due to the limited number of these masks and to their high cost throughout the country. Khader et al. ${ }^{19}$ indicated that $92.9 \%$ of dentists wore personal protective equipment such as masks, gloves, and goggles, and $96.2 \%$ of them frequently cleaned their hands by using alcohol-based sanitizers and soap and water. Furthermore, they reported that, although Jordanian dentists were aware of COVID-19 symptoms, its mode of transmission, infection control, and measures in dental clinics, they had limited comprehension of additional precautionary measures for protection of the dental staff and patients from COVID-19. However, there were no "local" cases in Jordan at the time of data collection.

When the working conditions of dentists are considered, they should always use personal protective equipment in dental clinics. However, dentists who are at high risk of COVID-19 have to take other measures during the COVID-19 pandemic. Samaranayake et al. ${ }^{20}$ indicated that rubber dam and strong saliva ejectors minimized aerosol or droplets during dental treatments. Furthermore, face shields/goggles should be worn to prevent the splashing or spattering of blood, saliva, and water droplets during treatment. It should not be forgotten that all dental professionals who continue to work during the pandemic are at high risk of COVID-19.

In this study, while $63.79 \%$ of Turkish dentists used strong dental suction during dental procedures, $49.95 \%$ avoided performing aerosol-forming procedures as much as possible. Among those dentists who started the treatment with a pre-procedural mouthrinse, $36.47 \%$ used $0.2 \%$ povidone (Batticon) and $10.32 \%$ used chlorhexidine. As instructed by the Guideline for the Diagnosis and Treatment of Novel Coronavirus-Infected Pneumonia ( ${ }^{\text {th }}$ edition) released by the National Health Commission of the People's Republic of China, it was reported that chlorhexidine, which is commonly used in dental practice, had no effect against COVID-19. Instead, mouthrinses containing oxidative agents such as $1 \%$ hydrogen peroxide or $0.2 \%$ povidone should be preferred. ${ }^{14} \mathrm{ADA}$ and $\mathrm{CDC}$ only recommend peroxide to destroy the virus. ${ }^{21,22}$

It is now confirmed that COVID-19 is transmitted through human contact and in the form of droplets, but airborne transmission has not been ruled out. ${ }^{23,24}$ Since the end of January 2020, it has been recommended that the Chinese avoid crowded places, including hospitals and dental clinics, as much as possible, to guard against cross-infection as a result of the rapid transmission of COVID-19.

COVID-19 spreads among people who are in close contact (within about 6 feet) with each other. The spread happens when an infected person coughs, sneezes, or talks, and droplets from their mouth/nose are released into the air and land in the mouths/ noses 
of people nearby, or the droplets are inhaled. It is a known fact that people who are infected but do not have symptoms are also likely to play a role in the spread of COVID-19. People can spread the virus before they know they are sick. Therefore, it is important to stay away from other people, even if they do not have any symptoms. Social distancing helps limit contact with infected people and contaminated surfaces. Social/physical distancing means a person should keep space between him/herself and other people outside the home. To practice social or physical distancing, a distance of at least 6 feet ( 2 meters) should be kept between people, and mass gatherings and gathering in groups should be avoided. Social distancing is especially important for people who are at higher risk because of their health conditions. ${ }^{25}$

In the literature, it has been indicated that many dental procedures have the potential to spread bacteria and viruses to the dental staff and other people in dental clinics. ${ }^{26}$ Health officials in some cities of China have ordered dental institutions to suspend all general non-emergency dental treatments, except emergency dental services. These policies have deterred patients from receiving dental care unless it is an emergency. ${ }^{23}$ Similarly, in Turkey, on the second day of the data collection in our study, the Turkish Ministry of Health and the Turkish Dental Association suggested that only emergency dental patients should be admitted during this process (March 17, 2020). Guo et al. ${ }^{23}$ reported that $94.6 \%$ of the dental visits during the COVID-19 epidemic were for emergency treatments. During this 5-day period, from the first day of data collection to the last day, physicians and health institutions significantly reduced patient admissions and mostly admitted emergency dental patients. The percentage of dentists who reported no changes in patient admissions in their institutions was $50.4 \%, 28.4 \%, 10.5 \%, 5.2 \%$, and $5.2 \%$, respectively, from day 1 to day 5 . The main reasons for this decrease were the results of the measures taken by dentists and authorities against the COVID-19 pandemic in view of the growing number of cases, and the instructions and controls recommended by CDC, ADA, WHO, the Turkish Ministry of Health, and Turkish Dental Association to dentists and dental staff.

Turkish dentists are mostly concerned about the lack of awareness of patients because of the problems they had in their workplace (41.30\%) during the COVID-19 pandemic. Among the dentists, $82.94 \%$ stated that they informed their patients about the COVID-19 pandemic, probably due to the low level of COVID-19 awareness among the patients. Khader et al. ${ }^{19}$ reported that the vast majority of dentists (97.8\%) thought that it was important to educate people about COVID-19 to prevent its spread. In addition, Turkish dentists (21.85\%) reported that they had difficulties reaching protective equipment (mask, shield, etc.) during the COVID-19 pandemic. Unfortunately, this has become a common problem for many countries in the world owing to the increasing demand for protective equipment and the increasing number of cases. The number of companies that manufacture protective equipment all over the world should be urgently increased, and the prices of these products should be reduced.

The major limitation of this study is that it is not known whether the dentists who participated in the study were infected with COVID-19. Whether there is a difference between dentists taking and not taking measures against COVID-19 could not be proven with concrete evidence. It would not be possible to contact the same participants for further studies since the participants' personal information was not recorded in this study.

\section{Conclusion}

The results of the survey conducted in this study reveal that, although Turkish dentists have increased protective measures against the COVID-19 pandemic, they have not reached sufficient levels yet in terms of attitudes and behaviors. However, further studies with a much larger sample size and longer follow-up period are needed to achieve more precise results. In addition, the prevalence of Turkish dentists infected by COVID-19 is definitely an issue to be investigated.

\section{Acknowledgements}

The authors wish to thank all participants for their invaluable contribution to this study. The authors express their deepest gratitude to all the healthcare professionals who contributed to the fight against COVID-19 and also dedicate this paper to all the Turkish healthcare workers who lost their lives because of COVID-19. 
Investigation of Turkish dentists' clinical attitudes and behaviors towards the COVID-19 pandemic: a survey study

\section{References}

1. Phelan AL, Katz R, Gostin LO. The novel coronavirus originating in Wuhan, China: challenges for global health governance. JAMA. 2020;323(8):709-710. https://doi.org/10.1001/jama.2020.1097

2. World Health Organization - WHO. Rolling updates on coronavirus disease (COVID-10). 2020 May 11. Available from: https://www.who. int/emergencies/diseases/novel-coronavirus-2019/events-as-they-happen

3. Chen L, Liu W, Zhang Q, Xu K, Ye G, Wu W, et al. RNA based mNGS approach identifies a novel human coronavirus from two individual pneumonia cases in 2019 Wuhan outbreak. Emerg Microbes Infect. 2020 Feb;9(1):313-9. https://doi.org/10.1080/22221751.2020.1725399

4. Cui J, Li F, Shi ZL. Origin and evolution of pathogenic coronaviruses. Nat Rev Microbiol. 2019/03/01 2019;17(3):181-192. https://doi.org/10.1038/s41579-018-0118-9.

5. World Health Organization - WHO. Coronavirus disease (COVID-2019) situation reports. 2020. Available from: https://www.who.int/ emergencies/diseases/novel-coronavirus-2019/situation-reports

6. Ibrahim NK, Alwafi HA, Sangoof SO, Turkistani AK, Alattas BM. Cross-infection and infection control in dentistry: Knowledge, attitude and practice of patients attended dental clinics in King Abdulaziz University Hospital, Jeddah, Saudi Arabia. J Infect Public Health. 2017 Jul - Aug;10(4):438-45. https://doi.org/10.1016/i.jiph.2016.06.002

7. Backer JA, Klinkenberg D, Wallinga J. Incubation period of 2019 novel coronavirus (2019-nCoV) infections among travellers from Wuhan, China, 20-28 January 2020. Euro Surveill. 2020 Feb;25(5). https://doi.org/10.2807/1560-7917.ES.2020.25.5.2000062

8. World Health Organization - WHO. Questions and answers on coronaviruses 2020. Available from: https://www.who.int, 2020c.

9. Meng L, Hua F, Bian Z. Coronavirus disease 2019 (COVID-19): emerging and future challenges for dental and oral medicine. J Dent Res. 2020 May;99(5):481-7. https://doi.org/10.1177/0022034520914246

10. World Health Organization - WHO Clinical management of severe acute respiratory infection when novel coronavirus (nCoV) infection is suspected. 2020.

11. Kohn WG, Harte JA, Malvitz DM, Collins AS, Cleveland JL, Eklund KJ. Guidelines for infection control in dental health care settings-2003. J Am Dent Assoc. 2004 Jan;135(1):33-47. https://doi.org/10.14219/jada.archive.2004.0019

12. Chen Y, Zhao Y. [Current situation and development of stomatological emergency medicine in China[J]. Chin J Pr Stomotol. 2016;9(7):385-9. Chinese.

13. Liu Y, Niu Z, Zhao J, et a I.[ Clinical analysis and countermeasures of 1206 night-time dental emergency cases in general hospital [J]. Chin J Geriat Dent. 2012;10(1):29-32. Chinese.

14. Peng X, Xu X, Li Y, Cheng L, Zhou X, Ren B. Transmission routes of 2019-nCoV and controls in dental practice. Int J Oral Sci. 2020;12(1):9. https://doi.org/10.1038/s41368-020-0075-9

15. Li ZY, Meng LY. [The prevention and control of a new coronavirus infection in department of stomatology]. Zhonghua kou qiang yi xue za zhi. 2020 Feb;55(0):E001. https://doi.org/10.3760/cma.j.issn.1002-0098.2020.0001.

16. Wang D, Hu B, Hu C, et al. Clinical characteristics of 138 hospitalized patients with 2019 novel coronavirus-infected pneumonia in Wuhan, China. JAMA. 2020;323(11):1061-1069. https://doi.org/10.1001/jama.2020.1585

17. Kampf G, Todt D, Pfaender S, Steinmann E. Persistence of coronaviruses on inanimate surfaces and their inactivation with biocidal agents. J Hosp Infect. 2020 Mar;104(3):246-51. https://doi.org/10.1016/i.jhin.2020.01.022

18. Centers for Disease Control and Prevention - CDC. Coronavirus disase 2019 (Covid-19): detailed disinfection guidance. Available from: https://www.cdc.gov/coronavirus/2019-ncov/prevent-getting-sick/cleaning-disinfection.html

19. Khader Y, Al Nsour M, Al-Batayneh OB, Saadeh R, Bashier H, Alfaqih M, et al. Dentists' awareness, perception, and attitude regarding COVID-19 and infection control: cross-sectional study among Jordanian dentists. JMIR Public Health Surveill. 2020 Apr;6(2):e18798. https://doi.org/10.2196/18798

20. Samaranayake LP, Reid J, Evans D. The efficacy of rubber dam isolation in reducing atmospheric bacterial contamination. ASDC J Dent Child. 1989 Nov-Dec;56(6):442-4.

21. Hendrick LG. Recommendations for the dentral practice in response to COVID-19. RDH. 2020 Mar 16. Available from: https://www.rdhmag. com/covid-19/article/14169838/recommendations-for-the-dental-practice-in-response-to-covid19

22. Centers for Disease Control and Prevention - CDC. Infection control: chemical disinfectants. Guideline for disinfection and sterilization in healthcare facilities (2008). Available from: https://www.cdc.gov/infectioncontrol/guidelines/disinfection/disinfection-methods/chemical.html

23. Guo H, Zhou Y, Liu X, Tan J. The impact of the COVID-19 epidemic on the utilization of emergency dental services. J Dent Sci. 2020 Mar 16. https://doi.org/10.1016/j.jds.2020.02.002

24. Li Q, Guan X, Wu P, Wang X, Zhou L, Tong Y, et al. Early Transmission dynamics in Wuhan, China, of novel coronavirus infected pneumonia. N Engl J Med. 2020 Mar;382(13):1199-207. https://doi.org/10.1056/NEJMoa2001316

25. Centers for Disease Control and Prevention - CDC. Coronavirus disease 2019 (COVID-19).Social distancing. Available from: https://www. cdc.gov/coronavirus/2019-ncov/prevent-getting-sick/social-distancing.html

26. Harrel SK, Molinari J. Aerosols and splatter in dentistry: a brief review of the literature and infection control implications. J Am Dent Assoc. 2004 Apr;135(4):429-37. https://doi.org/10.14219/jada.archive.2004.0207 


\section{Investigation of Turkish dentists' clinical attitudes and behaviors towards the COVID-19 pandemic: a survey study. Braz Oral Res. 2020;34:e054 DOI: 10.1590/1807-3107bor-2020.vol34.0054}

Table 4

Where is read:

Table 4. The importance levels of the related variables for the dentists' self-assessed COVID-19 knowledge score according to the MLP ANN model.

\begin{tabular}{|c|c|}
\hline The variables & $\begin{array}{l}\text { Importance } \\
\text { level (\%) }\end{array}$ \\
\hline Q23. As a dentist, do you inform your patients about Covid-19? & $15.39 \%$ \\
\hline Q12. Where do you receive the information about Covid-19 from? (multiple choice) & $7.79 \%$ \\
\hline Q1. Age & $7.44 \%$ \\
\hline $\begin{array}{l}\text { Q15. Which of the following measures do you implement in your professional } \\
\text { life against Covid-19? (multiple choice) }\end{array}$ & $7.42 \%$ \\
\hline $\begin{array}{l}\text { Q19. What are the problems you have encountered at work during this } \\
\text { Covid-19 pandemic? (multiple choice) }\end{array}$ & $7.34 \%$ \\
\hline $\begin{array}{l}\text { Q16. Which of the following measures do you apply to your patients in your } \\
\text { professional life against the Covid-19? (multiple choice) }\end{array}$ & $6.67 \%$ \\
\hline $\begin{array}{l}\text { Q14. Which of the following measures do you implement in your daily life } \\
\text { against Covid-19? (multiple choice) }\end{array}$ & $6.58 \%$ \\
\hline $\begin{array}{l}\text { Q17. Have you made any change individually regarding patient admissions in } \\
\text { your professional life against Covid-19? }\end{array}$ & $5.33 \%$ \\
\hline $\begin{array}{l}\text { Q22. Are you worried about transmitting this disease to your immediate } \\
\text { environment as a risky occupational group for Covid-19? }\end{array}$ & $4.80 \%$ \\
\hline Q4. Institution & $3.91 \%$ \\
\hline Q3. Specialty & $3.75 \%$ \\
\hline Q6. Who do you live with? & $3.51 \%$ \\
\hline Q2. Gender & $3.38 \%$ \\
\hline Q7. Do you have a child/ children? & $2.89 \%$ \\
\hline $\begin{array}{l}\text { Q18. Has the institution where you work made any change in its patient } \\
\text { admission policy owing to Covid-19? }\end{array}$ & $2.88 \%$ \\
\hline The day on which the questionnaire was filled out. & $2.35 \%$ \\
\hline $\begin{array}{l}\text { Q10. Have you had face-to-face contact with someone who traveled abroad in } \\
\text { the past month? }\end{array}$ & $2.00 \%$ \\
\hline Q8. Do you have a chronic illness/a disease that requires regular medication? & $1.62 \%$ \\
\hline Q13. Have you attended an informational meeting on Covid-19? & $1.54 \%$ \\
\hline $\begin{array}{l}\text { Q21. Are you concerned about being infected with this virus as a profession } \\
\text { group at high risk for Covid-19? }\end{array}$ & $1.35 \%$ \\
\hline Q9. Have you traveled abroad in the past month? & $1.12 \%$ \\
\hline Q20. Do you think that current events about Covid-19 affect you spiritually? & $0.91 \%$ \\
\hline Q5. Marital status & $0.03 \%$ \\
\hline Total & $100 \%$ \\
\hline
\end{tabular}




\section{It should read:}

The variables

Importance level (\%)

Q23. As a dentist, do you inform your patients about Covid-19?

15.39

Q12. Where do you receive the information about Covid-19 from? (multiple choice)

Q1. Age

Q15. Which of the following measures do you implement in your professional life against Covid-19? (multiple choice)

Q19. What are the problems you have encountered at work during this Covid-19 pandemic? (multiple choice)

Q16. Which of the following measures do you apply to your patients in your professional life against the Covid-19? (multiple choice)

Q14. Which of the following measures do you implement in your daily life against Covid-19? (multiple choice)

Q17. Have you made any change individually regarding patient admissions in your professional life against Covid-19?

Q22. Are you worried about transmitting this disease to your immediate environment as a risky occupational group for

Q6. Who do you live with?

Q2. Gender

Q7. Do you have a child/ children?

Q18. Has the institution where you work made any change in its patient admission policy owing to Covid-19?

The day on which the questionnaire was filled out.

Q10. Have you had face-to-face contact with someone who traveled abroad in the past month?

Q8. Do you have a chronic illness/a disease that requires regular medication?

Q13. Have you attended an informational meeting on Covid-19?

Q21. Are you concerned about being infected with this virus as a profession group at high risk for Covid-19?

Q9. Have you traveled abroad in the past month?

Q20. Do you think that current events about Covid-19 affect you spiritually? 